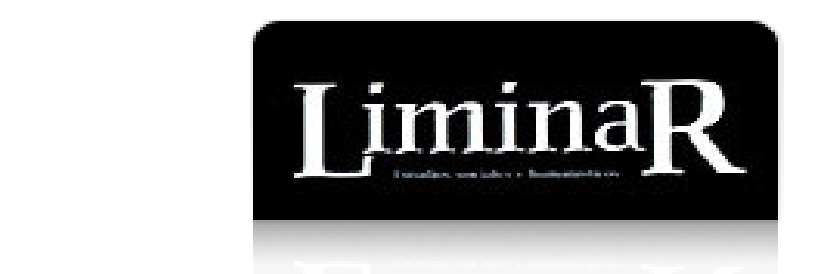

LiminaR. Estudios Sociales y Humanísticos ISSN: $1665-8027$

liminar.cesmeca@unicach.mx

Centro de Estudios Superiores de México y Centro América

México

Basail Rodríguez, Alain

DESARROLLO Y POLÍTICAS CULTURALES ADAGIO AL DISCURSO Y AL RECURSO DE LA CULTURA

LiminaR. Estudios Sociales y Humanísticos, vol. III, núm. 1, junio, 2005, pp. 74-99

Centro de Estudios Superiores de México y Centro América

San Cristóbal de las Casas, México

Disponible en: http://www.redalyc.org/articulo.oa?id=74511477006

- Cómo citar el artículo

- Número completo

- Más información del artículo

- Página de la revista en redalyc.org

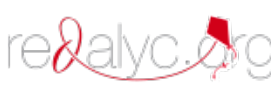

Sistema de Información Científica

Red de Revistas Científicas de América Latina, el Caribe, España y Portugal Proyecto académico sin fines de lucro, desarrollado bajo la iniciativa de acceso abierto 


\title{
Desarrollo y Políticas Culturales Adagio al discurso y al ReCURSo de la CUltura
}

\author{
Alain Basail Rodríguez
}

\begin{abstract}
Alucinados por el progreso, creímos que avanzar era olvidar, dejar atrás las manifestaciones de lo mejor que hemos hecho, la cultura riquísima de un continente indio, europeo, negro, mestizo, mulato, cuya creatividad aún no encuentra equivalencia económica, cuya continuidad aún no encuentra correspondencia política.
\end{abstract}

Carlos Fuentes, 1997:1

$\mathrm{E}$ stas notas acerca de los vínculos entre cultura, política y desarrollo nacen del interés por contribuir a la comprensión de las implicaciones socioculturales referidas a políticas y proyectos de desarrollo, a la sensibilización de los planificadores teniendo en cuenta la importancia de la cultura y, por último, a perfilar algunos factores o componentes culturales de los procesos de cambio social. Advierto que el nivel de generalidad de las ideas expuestas busca trascender lo estrictamente particular para reflexionar sobre algunas sospechas de las múltiples dimensiones que entraña la relación desarrollo-cultura y además, con modestia, formular proposiciones teóricas sobre el papel fundamental de las políticas culturales y de la agencia humana en la constitución así como dinámica cultural de las sociedades contemporáneas.

\section{Desarrollo y Cultura: convergencia conceptual}

Los conceptos de desarrollo y cultura han llegado a convertirse en palabras-fetiches. No porque todos los conceptos lo sean de alguna manera, al pretender describir con cierta precisión una categoría coherente de fenómenos socialmente relevantes, sino porque han actuado como poderosos "filtros intelectuales" en la comprensión del mundo y las formas de actuar en él (Viola, 2000:11). Sin duda, ambos constituyen ideasfuerzas directrices del pensamiento y la acción en los tiempos modernos, siendo de los más densamente embebidos de ideología de todo el siglo XX. De manera que evocan una red de significa-dos bastante opacos y frágiles en la que se está irremediablemente atrapado a la hora de plantear la ardua tarea de su reconstrucción teórica. Tarea que de ninguna manera se pretende asumir en este ensayo. No obstante, sí se apuesta por problematizar sobre la siguiente proposición: cuando se invoca discursivamente a la cultura y al desarrollo, se conjura, busca y realiza algo en cuyo sentido hay que centrarse para comprenderlos.

La idea de desarrollo ha estado determinada por visiones economicistas, eurocéntricas y androcéntricas (Cambra, 2002). La ideología del desarrollo se forjó en torno a la idolatría del progreso tecnológico, la visión funcionalista del mismo y la racionalidad instrumental. Esta ideología presupuso, más que un repertorio de

Alain Basail Rodríguez, Centro de Estudios Superiores de México y Centroamérica. Universidad de Ciencias y Artes de Chiapas. 
teorías económicas o de soluciones técnicas, una determinada concepción de la historia de la humanidad y de las relaciones entre el hombre-naturaleza, entre los propios hombres y, también, un modelo implícito de sociedad que generalmente se consideró como universalmente válido y deseable. Dicha concepción del tiempo histórico fue definida en términos de la laica y moderna "idea de progreso", sustituta de la cristiana y medieval "idea de la providencia" (Gray, 2004; Cambra, 2000:1). De tal modo, han gobernado la fe en las propiedades desmistificadoras de la ciencia, la perfectibilidad del hombre y de la humanidad, la combinación de positivismo — separación de valores y hechos- y monismo — una única respuesta—, hasta conferirle un creciente poder social a los "expertos", privilegiar un enfoque tecnocrático de los problemas sociales e imponer la creencia tendente inevitable a la homogeneidad y desaparición de la diversidad cultural. Todo ello alrededor de un estado más o menos protagónico en relación con la centralidad del mercado, no sólo como espacio de relaciones comerciales sino, como advirtió el viejo Marx, en tanto generalización de un modo de representar sujetos, procesos y objetos regidos por la lógica del fetichismo.

Asimismo, las ficciones del encantamiento modernizador cristalizaron alrededor de una "idea de cultura" que sustituyó a la "idea de la Gracia" como cemento ideológico de la sociedad (Bueno, 1997). Precisamente por ello, la cultura ha constituido un mito moderno modulado para dignificar, abstraer y neutralizar cuanta práctica y discurso social puede alcanzarse a imaginar $y$, sin extrañamientos, se ha redefinido en espurios términos "nacionales", de "élite" o de "masa".

En el discurso político del estado nacional la cultura ha sido, entre otras, un fundamento. Su proyecto opera con eficacia la homogeneidad e integra a la "sociedad nacional" como un todo, basado en políticas que delimitan fronteras físicas y simbólicas, controlan, disciplinan y patrimonializan símbolos, valores y lengua legítima. De manera que los múltiples usos de la cultura a partir de apropiaciones sociopolíticas, educativas y económicas no dejan de acrecentarse hoy cuando se habla de mejorar las condiciones de vida, promover la tolerancia entre culturas, la participación cívica y, fundamentalmente, cuando todo indica que la reproducción del sistema de relaciones capitalistas se culturaliza.

Las crisis sociales como crisis de los modelos de desarrollo que abrieron profundas brechas humanas, ecológicas y regionales, trajeron consigo, sobre todo a partir de los años 60 , un cuestionamiento ético y estético de las consecuencias perversas de esta modernidad; los efectos materiales y simbólicos, medioambientales y culturales de la racionalidad científica: la fe ilimitada en el progreso. Del mismo modo, ha sido una crítica a la falacia objetivista del desarrollo basado en la materialidad tecnoeconómica y el consumismo voraz al margen de los marcos culturales; también, a la escatología del desarrollismo y a sus impulsos salvacionistas que endiosaron al mercado bajo el principio del laissez-faire y hasta contribuyeron a regular el cuerpo para transformarlo en un bien de consumo. Entonces, comenzó un reconocimiento explícito del papel del medio ambiente como recurso para el desarrollo y un llamado conservacionista para conciliar los intereses nacionales y globales frente a los estilos de producción y consumo irracionales y despilfarradores (PNUD, 1998). Asimismo, como un reclamo de sostenibilidad para garantizar la satisfacción de las necesidades de las presentes y futuras generaciones. Sin embargo, los principios medio-ambientalistas y de sostenibilidad se han sometido a un nuevo reduccionismo así como a una desvirtuación ideológica hasta perder cierto contenido "crítico" inicial (Celecia, 1997:59).

Las características de, y los criterios para alcanzar un desarrollo sostenible en términos ecológicos, fueron complementados por la propuesta de desarrollo 
humano definida en los Informes del Programa de las Naciones Unidas para el Desarrollo (PNUD, 1990-1998). $\mathrm{Al}$ crecimiento económico se añaden criterios de beneficio y equidad social para regenerar el medio ambiente y potenciar a la persona. El nuevo énfasis en la agencia humana — su dignidad y decencia — suma al telos del proceso de desarrollo niveles o dimensiones donde se recuperan los valores de sostenibilidad y seguridad, al tiempo que entran en juego otros como la potenciación del hombre, la cooperación y la equidad social (PNUD, 1999:62-63). Todo esto, siempre, dentro del modelo de desarrollo y las relaciones sociales dominantes en la modernidad, sin cuestionar sus límites.

Durante la época culmen de la teoría de la modernización, las culturas de las sociedades del tercer mundo fueron percibidas como los obstáculos fundamentales para su desarrollo, en la medida en que dichas culturas eran identificadas con actitudes de fatalismo, inmovilismo y oscurantismo, y con estructuras sociales obsoletas por tradicionales o premodernas (Viola, 2000:16). Una crítica de estos presupuestos supuso reconsiderar el papel de la cultura en la mediación de los procesos sociales de cambio tecnológico, económico, político, y en la reconstrucción de un mundo conflictivo y crísico. En los años 70 se produjo un llamamiento a la descolonización de la mente, se promovió una forma de pensar, de presentar a las sociedades del sur ajena a los discursos y prácticas dominantes, a una vulgar concepción materialista del desarrollo. Así, junto con la diversidad biológica y regional, se comenzó a reivindicar la diversidad cultural como "fuente de energía social y de desarrollo", a defender los derechos culturales y la ciudadanía cultural, $\mathrm{y}$ a plantear las profundas y complejas relaciones entre cultura y desarrollo. Por ejemplo, expertos de la UNESCO lo abordaron como "desarrollo cultural" para rechazar "la necesidad" o "la posibilidad" de la imitación mecánica de las sociedades industriales, también para promover la responsabilidad, la voluntad y el compromiso en un desarrollo con democracia, equidad y participación. A pesar de tomar debida nota de las particularidades de cada entidad, no se evitaron las contradicciones teóricas y prácticas de pretender un desarrollo propio o autárquico, que conduciría inevitablemente a estados superiores, o al impulso direccionado del cambio — tal autarquía es aún promovida con ingenuidad por algunos- No obstante, de esta manera empezó a verse el papel de la cultura y de la agencia humana en el desarrollo como proceso multidimensional y meta compleja. Paulatinamente durante la década de los 90, la valoración del "capital cultural" en las estrategias de desarrollo sustituyó a los fracasos de la inversión en "capital físico", "capital humano" o "capital social" de las décadas precedentes (Yúdice, 2002:28). De manera que en las discusiones actuales sobre los problemas del desarrollo se habla de la dimensión humana, ecológica, y de criterios de "sustentabilidad" o "sostenibilidad", así como de una ineludible dimensión cultural.

En contra de lo que se pensaba, la era de la globalización no ha venido marcada por una tendencia hacia la lisa y llana homogeneización cultural del mundo o mundialización; más bien, se caracteriza por una "transculturalidad planetaria", una especie de sincronización del desarrollo capitalista con un alcance geográfico y unas metas que imaginan al mundo de una manera que parece menos moderna, sin llegar a serlo plenamente porque se extrema en sus dramas civilizatorios.

La cultura como recurso económico se legitimó e impuso sobre otras interpretaciones hasta situarse en el seno del proceso de producción y reproducción ampliada del valor como esencia de la sociedad capitalista (Acanda, 2002:13). En tanto, la racionalidad económica absorbió la producción cultural ya que subsume a los productos culturales en la lógica de las mercancías para controlar la producción de valor, "...la gestión, la conservación, el acceso, la distribución y la 
inversión" (Yúdice, 2002:13), y el propio consumo de las mercancías culturales a través de mecanismos que ejercen una profunda violencia simbólica.

La cultura como recurso cobra legitimidad entre los políticos que deciden la inversión y protección culturales por su valor utilitario para disminuir los conflictos, procurar justicia social e impulsar el desarrollo económico; para, de esta manera, fortalecer a la sociedad civil como soporte del desarrollo del capital, promover el desarrollo del turismo, de las industrias culturales en general y de todas las que dependen de la propiedad intelectual. Esto ha resultado bien complejo en la sociedad de flujos globales de bienes materiales y simbólicos, y del movimiento del trabajo manual e intelectual, porque tal lógica cultural planetaria dinamita la unidad de las sociedades nacionales al multiplicarse las identidades locales o supranacionales. El valor instrumental de la cultura y su dinámica global complica la cuestión de la soberanía nacional en la medida en que la cultura comienza a transterritorializarse cuando el papel de las industrias culturales, la ley de propiedad intelectual y los derechos de autor, marcan la pauta de la nueva lógica de acumulación del capital.

Horkheimer y Adorno, al criticar a las industrias culturales, atacaron a la ciencia y a los sistemas tecnoculturales en cuanto instancias que socavaban los auténticos sistemas de significados, por ello apuntaron a los efectos inmediatos de los artefactos tecnológicos "post-auráticos" generados por sistemas de producción de masas.

La industria cultural que había desublimado y despojado de sus contenidos racionales a la cultura, se dispuso a ser utilizada con vistas a un control persuasivomanipulativo de las conciencias (Mattelart y Piemme, 1985:88). Sin duda, los representantes del pensamiento crítico fueron finos al advertir que "la cultura" perdía autonomía incorporada al engranaje económicoadministrativo y, más allá de sus nostalgias ilustradas, la historia les hizo justicia en la medida en que se acentúa la conformación de conglomerados multimedias como parte del proceso globalizador de la cultura y de las políticas de privatizaciones de las empresas públicas. Éstos expanden e internacionalizan los servicios de producción como parte del nuevo modelo posfordista. Ello es palpable, por ejemplo, cuando la industria del cine, del audiovisual en general, obtiene jugosos dividendos a partir de la especialización flexible que permite diferenciar los modos de producción, segmentar los mercados de consumo cultural, fijando nociones de proximidad y distancia cultural, narrativas de identidad, formas de conocimiento transculturales. Esto ocurre cuando los estados latinoamericanos han reducido sus gastos en servicios sociales y, fundamentalmente, el financiamiento de programas educativo-culturales, así como la inversión en investigación científica durante las últimas décadas (Wortman, 2001:254); cuando, sobre todo, son notables sus debilidades para regular las transformaciones económicas que caracterizan a la actual división internacional del trabajo.

Parece perderse de vista que las nuevas fuentes de acumulación del capital y de crecimiento económico dependen de la propiedad intelectual y los derechos de autor como formas culturales constitutivas de la sociedad del conocimiento. Los contenidos en manos de los productores y distribuidores abarcan desde los softwares y portales de internet hasta las formas de conocimiento no occidentales. Ahora, ¿qué propiedad se ha de proteger de acuerdo con qué principios?, ¿qué beneficios obtienen los legítimos dueños del conocimiento? Los creadores se han convertido en trabajadores culturales, las culturas en proveedoras de contenidos sobre los que no se tiene más derecho que el fijado en contratos dilapidarios que permiten las leyes injustas donde se favorece a las corporaciones.

En un par de libros inspiradores de estas reflexiones, George Yúdice afirma que las industrias del entretenimiento y de los derechos de autor — música, 
filmes, vídeos, revistas y televisión—, son las que más aportan al Producto Interno Bruto (PIB) de Estados Unidos de América (EUA) (2002; y Miller, 2004). También en México su contribución económica es muy significativa (Piedras, 2004). De manera que la localización y la circulación de bienes simbólicos y sus dividendos alcanzan volúmenes inusitados en el comercio mundial. No es de extrañar que el Banco Mundial (BM), el Banco Interamericano de Desarrollo (BID) y numerosas fundaciones hayan comenzado a invertir en la cultura como esfera económica de creciente importancia. La circulación de las riquezas desmaterializadas es regulada y coordinada según el Acuerdo General sobre Aranceles Aduaneros y Comercio (GATT) y, su émula, la Organización Mundial del Comercio (OMC) a la que se adhirieron un gran grupo de Estados que al firmar los acuerdos de Marrakech, signaron, al mismo tiempo, el Acuerdo General sobre Comercio de los Servicios (AGCS) (Miller y Yúdice, 2004:231-237). Sin embargo, la cuestión del uso y apropiación de los productos culturales ha provocado encendidas discusiones en éstos y otros foros internacionales en torno a su valor mercantil o cultural, su significado para la economía o las identidades. A pesar del enfrentamiento entre tirios y troyanos, encarnados por estadounidenses o franceses y el tercer mundo, la "regularización” progresiva del grado de liberalización continúa siendo una asignatura pendiente $-\mathrm{O}$, mejor, contraproducente-, pues se percibe como una fuerte amenaza que: "Todos los aspectos de las políticas, nomenclaturas, reglamentaciones internas y políticas de subvención, acceso a los mercados públicos, están sometidos a las pruebas de lo “comercialmente correcto"” (Bourdieu, 2004:554-555). De hecho, en los acuerdos de "libre" comercio los apéndices culturales tienen reservados pequeños espacios, más bien orlativos, que obliteran las cuestiones culturales, ${ }^{1}$ puesto que los Estados se verían obligados, entre otras cosas, a profundizar en la discusión (supra)nacional sobre la desaparición de la noción de servicio público, la negación o el reconocimiento de la diversidad cultural, de las necesidades reales de las comunidades diferentes, es decir, sobre la participación democrática, "el interés general", los derechos de ciudadanía política, civil, social y, sobre todo, cultural. Estos acuerdos siguen la pauta del AGCS de someter y, paulatinamente, suprimir las restricciones nacionales sobre el comercio en todos los sectores de servicios — educación, sanidad, audiovisuales y cultura, en general - o, en otras palabras, abrir todos los servicios públicos a las leyes del libre comercio para promover la competencia y la eficacia económica. Habida cuenta de un tráfico acelerado de la cultura como recurso por la globalización, las instituciones globales tratan de gerenciar la nueva división internacional del trabajo cultural basada en la brecha entre la inversión y administración transnacional y las diferencias nacionales o locales. Tal como se negocian las cosas en la OMC y su AGCS, las leyes de la competencia sujetan y subordinan a las legislaciones nacionales, otrora instrumentos medulares de la soberanía y del desarrollo a partir de las particularidades locales, regionales y nacionales. Paralelamente, otras instituciones se han visto obligadas a valorar, al menos, la diversidad cultural y la cultura misma en un sentido antropológico del desarrollo. La Organización de las Naciones Unidas (ONU) promovió el Programa "Decenio Mundial para el Desarrollo Cultural" entre 1988 y 1997, con el principal objetivo de fomentar la toma de conciencia de la relación entre cultura y desarrollo. Mientras, su órgano para la educación y la cultura (UNESCO), pasó a considerar la dimensión cultural del desarrollo como una variable esencial de cualquier proyecto, tan relevante como los factores técnico-económicos; presentó el Informe Nuestra Diversidad Creativa (unesco, 1996) que promueve la instrumentalización de la cultura y la justicia social; y convocó a la Conferencia Intergubernamental sobre Políticas Culturales para el Desarrollo (UNESCO, 1998). 
Sin embargo, la UNESCO no ha enfatizado en la incompatibilidad de su programa con el AGCS, más bien se ha adherido al mismo (Bourdieu, 2004).

El giro hacia la cultura se produjo, también, al constatarse que una de las principales causas del fracaso de muchos proyectos de desarrollo en el Tercer Mundo fue su escasa adecuación al marco cultural de las poblaciones destinatarias (Viola, 2000:21). Algunos estudios antropológicos, como los editados por Viola, han dado cuenta del discurso y las prácticas de las instituciones del desarrollo y de las comunidades locales frente a dichas propuestas, así como de sus consecuencias sociales y las respuestas ad hoc. De hecho, se ha subrayado cómo el olvido o infravaloración de la dimensión cultural del desarrollo está detrás de innumerables fracasos. La adecuación cultural del desarrollo es una cuestión crucial que suele tener una incidencia directa sobre su éxito o su fracaso final. El antropólogo Corand P. Kottak, siendo asesor del Banco Mundial, revisó 68 proyectos rurales financiados por esta institución y demostró que sólo fueron exitosos los proyectos "culturalmente compatibles", es decir, aquellos que tuvieron en cuenta o fueron respetuosos con los patrones culturales locales; basados en instituciones preexistentes y que incorporaban prácticas y valores tradicionales (Kottap, 2000:103-128).

Estas observaciones actualizan la discusión sobre por qué tener en cuenta la dimensión cultural de la vida social es de vital importancia para el desarrollo social y humano. Las respuestas refuerzan la idea de que la cultura es una variable crucial para el éxito de cualquier proyecto de desarrollo. De hecho, varias coinciden en reconocer que no se debe emprender ningún proyecto de transformación individual, grupal o comunitario sin tener en cuenta las costumbres, las tradiciones, los valores, las normas, los símbolos y los significados compartidos por los individuos de la colectividad "destinataria"; por lo menos, se celebra declararlo discursivamente.
La necesidad de respetar la territorialidad e incorporar la cultura de las poblaciones destinatarias en las iniciativas de desarrollo económico, llevó a autores como Bonfil Batalla y Rodolfo Stavenhagen a hablar de etnodesarrollo o desarrollo con autoconfianza - ejercicio de la capacidad social de un pueblo para construir su futuro, mirar hacia adentro y buscar en la propia cultura(Viola, 2000:22); de desarrollo de abajo hacia arriba (Gimo Omo-Fadaka); e, incluso, de desarrollo participativo y no excluyente (Orlando Fals Borda y Anisur Rahman). También salen de la marginalidad los enfoques de desarrollo económico local (Arocena, 1995; Alburquerque, 2004), y desarrollo endógeno (Vázquez Barquero, 2002), para resituar los problemas del desarrollo en escalas micro o meso sociales - locales o regionales - en articulaciones horizontales de abajo a arriba y en la integración flexible y complementaria de los diversos actores del entramado productivo a partir de sus identidades y especificidades territoriales. Todas estas propuestas han entendido, de una manera más o menos explícita, a la cultura local como un catalizador del desarrollo.

En un artículo originalmente publicado por el Banco Mundial (2004), Amartya Sen resume algunas categorías que considera de primordial necesidad y relevancia para identificar con más precisión las maneras en que la cultura importa para el desarrollo entendido en un sentido amplio y complejo, a saber: 1. como una parte constitutiva del desarrollo en tanto fortalecimiento del bienestar y de las libertades; 2. a través de objetos y actividades económicamente remunerativas — como el turismo cultural-; 3. por la influencia sobre el comportamiento económico de factores culturales -éticos y del comportamiento humano-; 4. mediante el papel de las condiciones culturales en la participación política y en los intercambios cívicos virtuosos; 5. por el propio funcionamiento de la solidaridad social y el asociacionismo para el apoyo mutuo: 6 . por explorar sistemáticamente la historia cultural, de parajes o 
patrimonios culturales, y rememorar esa herencia histórica; y 7. las influencias de los factores culturales en la formación y evolución de los valores, en la identificación de los fines y los medios del desarrollo (Sen, 2004:24-26).

Sin embargo, el protagonismo de la cultura en las discusiones sobre el desarrollo adquiere, a veces, cínicas connotaciones de moda efímera y de una pose políticamente correcta fomentada por los debates sobre el ethos cultural de esta modernidad tardía. Es más, la reconsideración de la importancia de la cultura no ha estado exenta de engaños y espejismos relacionados con oportunismos intelectuales - "heroicos"-, como los de Lawrence Harrison y Samuel Huntington en Culture Matters al "contar", en particular este último, las diferencias entre Ghana y Corea del Sur para demostrar de manera sugestiva y determinista que en el desarrollo: "...En pocas palabras, las culturas cuentan" (Huntington apud. Sen, 2004:27). Como veremos, todos los agentes del desarrollo afrontan de una manera u otra estas falaces reducciones que expresan lógicas de pensamiento y de la cultura trabadas en inmensas semiosis perceptivas, en nombre de las cuales se actúa sin reconocer la autonomía de la cultura del "otro".

Entonces, convengamos que si el desarrollo debe ser comprendido en tanto que proceso sociocultural extenso y enrevesado, las intervenciones a través de programas o acciones concretas deben ser legítimas culturalmente hablando. La legitimidad de la gestión o apropiación de la "ganancia" de los recursos naturales y culturales es, en principio, lo que está en disputa. Dicha legitimidad se ha logrado en diferentes experiencias con la introducción de una dimensión más participativa y más respetuosa con las culturas locales e, incluso, dando a éstas una capacidad de acción —empowerment - que potencie sus competencias y recursos, y no que sustituya sus estrategias y tácticas por otras de dudosa plausibilidad. Esto implica acentuar el debate sobre la necesidad de incorporar el conocimiento local como base de un desarrollo sustentable, y la asimilación selectiva de aportaciones tecnológicas y culturales de otras sociedades. Ahora bien, ¿cuáles son los obstáculos con los que se tropieza? Quizá algunas pistas se pueden encontrar yendo de la cultura del desarrollo de los agentes, al desarrollo de la cultura que se desea y a los medios para alcanzarlo.

\section{De la cultura del desarrollo...}

Generalmente se reconocen cuatro niveles de cultura en el desarrollo: local, regional, nacional y transnacional. A ellos debe añadirse un quinto nivel que corresponde al de los planificadores — con objetivos propios, redes de comunicación, flujos de información, líneas de autoridad, imperativos territoriales, recompensas y castigos - L La singular subcultura de los planificadores, especialistas, científicos e ingenieros, es la que lleva a justificar el cambio en función de "metas abstractas" y la naturaleza técnica de un trabajo acorde con intereses y cosmovisiones racionalistas y tecnológicas (Gouldner, 1980). Ello se traduce, en muchos casos, en proyectos carentes de sensibilidad social y alejados de la percepción de las necesidades locales. Cuando los organismos internacionales, incluidas ONG, ignoran la diversidad cultural y adoptan un mismo enfoque con tipos muy diferentes de "beneficiarios" en contextos con recursos específicos, se alejan de la necesidad de alternativas culturalmente apropiadas. Lo que produce la falta de sensibilidad hacia la cultura local es el elitismo correlativo a la formación occidental, la interpretación instrumental del saber, las relaciones verticales, las modulaciones unilaterales del pensamiento, cierto mesianismo y el consecuente aislamiento respecto a los procesos reales. Al parecer el reto pasa, pues, por encajar las propuestas e iniciativas de cambio en y con las necesidades locales a través de una asimilación crítica y desnaturalizante de las relaciones sociales. ${ }^{2}$

Los antropólogos del desarrollo han demostrado que tras esa falta de sensibilidad hacia las culturas locales/ nacionales y los dictados de lo que se debe hacer o ser 
bajo un discurso racionalista y maximizador basado en la constatación objetiva de resultados, se oculta un problema de negación de alteridad. Es decir, la acción cultural en pro del cambio social deviene en nombre de una racionalidad que no hace otra cosa que participar de lógicas de dominación que niegan el "yo" al reducir los valores y principios culturales que identifican y diferencian a los grupos humanos. Cuando esa percepción simplista o simplificadora de la alteridad conduce a la negación de humanidad, al deterioro de la identidad del otro, estos procesos adquieren carácter de drama civilizatorio donde campea el racismo de clase, intelectual, de color de la piel, de género, de culturas, de naciones. Por eso, es un imperativo reconocer con sinceridad y honestidad que estas posiciones ambiguas caracterizan a la generalidad de los intelectuales cuyo pedantismo, mundanería y altanería se constata con los profesionales que obran en nombre de la conciencia teorética o cientificista, los políticos que actúan (o no) en nombre de ciertos ideales sociales, y los funcionarios o programadores de instituciones nacionales o internacionales que lo hacen, generalmente, en nombre de principios organizacionales o de los valores culturales hegemónicos de occidente.

No deja de ser curioso que se viva una época en la que la proliferación de expertos en la evaluación de riesgos, ejecuciones y resultados se acompaña, paradójicamente, de la ausencia de datos que dificulta o imposibilita las predicciones serias; y, luego, si esos datos están disponibles, la falta de democracia política obstaculiza las tomas de decisión y la modulación de las políticas (Alexander, 2000:7).

¿Cómo establecer una mediación entre la cultura de los expertos y las prácticas cotidianas? Para intentar responder a esta pregunta debe cuestionarse, también, el carácter de los diseños culturalmente desfasados de contextos específicos que se basan en, por ejemplo: a) los grupos sociales y el concepto de propiedad euroamericano — unidades productivas individuales-; b) los sistemas cooperativos inspirados parcialmente en modelos que se utilizaron en los países ex socialistas del Este - sin acceso directo al mercado, falta de motivación, confianza y atención individualizada en las cooperativas más grandes y, la inestabilidad del personal de las pequeñas porque los salarios estaban por debajo de los que se obtenían en el trabajo privado-; o c) las políticas de identidad o de discriminación positiva que suponen ejes de desigualdad raciales, genéricos, clasistas o religiosos que operan sociohistóricamente de modo similar al caso norteamericano, es decir, imponiendo representaciones que tienden a racializar la vida de otros pueblos. Ante esos posibles modelos culturalmente desfasados se impone un análisis a profundidad de las organizaciones locales para identificarlas y aprovecharlas como recurso para el desarrollo. La principal propuesta de los antropólogos del desarrollo consiste, precisamente, en usar los principios de la sociedad tradicionalpara estructurar una nueva. De manera que, como se ha insistido, el obstáculo más notorio del discurso científico pasa por su capacidad de representación del otro.

La propuesta se basa, siguiendo a Kottak (2000), en un mayor uso de modelos del tercer mundo para el desarrollo del tercer mundo. La compatibilidad cultural de los proyectos por el aprovechamiento de los recursos existentes, de las organizaciones tradicionales, implicaría beneficios económicos y sociales porque los objetivos para el cambio remiten a las percepciones locales, así como a la definición de diseños adecuados y flexibles para su puesta en marcha. Ello se traduciría en participación y compromiso con el bienestar colectivo, aunque su límite consista en el supuesto hipotético de lograr trascender los antagonismos entre los ethos culturales de los actores en interacción. Para retomar un ejemplo anterior, las cooperativas suelen tener más éxito en países del sur cuando aprovechan instituciones comunales de alcance local ya existentes. Se debe a que los grupos participativos suelen ser más eficaces cuando se basan en organizaciones sociales 
tradicionales o en alguna similitud sociológica o antropológica como los grupos étnicos, de parentesco, los lazos tradicionales — apego a la tierra, accidentes geográficos, compartir medios de riego-, por contingencias históricas —expulsiones, migraciones, accidentes o catástrofes-, o redes sociales con el liderazgo de figuras religiosas o cabezas de los grupos de filiación.

El desarrollo técnico-económico, político y social no puede entenderse al margen de un marco cultural cuyas connotaciones definen las elecciones apropiadas, los usos legítimos y los riesgos experimentales que asumen los hombres. Hay lógicas de la cultura que constituyen un conjunto de tramas insertas en lo social que mantienen vivos a los hombres, al contrario que las lógicas económicas. Ejemplos muy significativos se pueden encontrar en los campos de la medicina y la educación. La medicina cosmopolita enfrenta resistencias y conflictos entre muchos pueblos porque la enfermedad es una construcción cultural: la concepción holística de la salud y la enfermedad se enfrenta al modelo médico hegemónico de carácter biologicista, individualista, ahistórico y asocial. Equiparar salud con dependencia de los servicios médicos es reconocer la falta de doctores, centros de salud, hospitales y medicamentos. Ahora, si la salud es entendida como la capacidad autónoma para enfrentarse con el medio ambiente, se regenera la capacidad curadora, la sabiduría popular, la riqueza de la capacidad curativa del entorno, de las redes de amigos y, más allá de lo tradicional, de la colaboración externa - esto según el propio concepto de la Organización Panamericana de la Salud (Barfield, 2001:81-89; 235-237).

Por otra parte, la educación es más que acumular diplomas como dicta la definición económica del aprendizaje. Dicha concepción de la educación se enfrenta a cómo se reinserta el aprendizaje en la cultura a partir de un flujo constante que enriquece los conocimientos, la sabiduría, a través de la ayuda y el intercambio social - por ejemplo, alrededor de los abuelos y padres en la comida o la sobremesa familiar-. Equiparar educación con institucionalidad es reconocer la falta de maestros y escuelas, y no con un proceso social amplísimo donde el protagonismo de todos los miembros de la sociedad en la transmisión de conocimientos es incuestionable e irremplazable por aquéllos o por los medios audiovisuales. Identificar educación con instrucción es reducir el proceso de aprendizaje al plano cognitivo, descuidar la formación amplia, integral, de los hombres-ciudadanos del futuro para vivir y aprender en colectivo. Invertir en educación para desarrollar el capital social y humano, como recomiendan el MB, el FMI e, incluso, la Comisión Económica Para América Latina (CEPAL), es de vital importancia pero sólo una parte del problema, y no la "solución mágica" para alcanzar el desarrollo en medio de las relaciones de mercantilización que envuelven al sector. La aparente complejidad del asunto se desempapela cuando vemos, sobre todo, que la educación va dejando de ser un derecho público para ser un privilegio reservado a algunos con dinero para la educación de pago, en detrimento del servicio gratuito como derecho universal de ciudadanos que devienen en consumidores, al parecer ineludiblemente (García Canclini, 1995; Bourdieu, 2004:557).

De manera que los servicios educativos y culturales devienen, más que derechos fundamentales, fuentes de beneficios y mercancías transformadas por empresas privadas según la lógica de las leyes del mercado. No se pierda de vista que con políticas nacionales liberalizadas, como articuladoras de una estrategia de desarrollo en tiempos de globalización, se crea una realidad cultural con claros intereses de legitimidad e integración sociocultural de la comunidad (trans)nacional. En esos procesos de pretendida distribución de saber-poder, la cultura se presenta como una variable concreta identificada generalmente con la 
"alta cultura" — museos de arte, gusto musical refinado, índices de lectura - o el conocimiento científico-técnico reproducido en las universidades. Pero ¿realmente se toman en cuenta las demandas de empleo que garantizarían la incorporación al mercado laboral concluidos los estudios?, ¿es ello congruente con las culturas y las estrategias de desarrollo locales y regionales?

El problema de un orden más igualitario y equitativo no sólo se resuelve con propuestas culturales plausibles, con políticas universalistas y homogeneizadoras que obvien las diferencias de rangos o prestigio social, en síntesis, la estructura socioeconómica en diferentes escalas. Una cuestión principal que se encuentra detrás de estos asuntos tiene que ver con las armazones epistémicas de acuerdo con las cuales actúan los agentes del desarrollo. Quizá un ejemplo logre ilustrar este punto con el que subrayamos los dilemas culturales en el desarrollo. La "pobreza" no es el problema social de fondo que hay que estudiar para poder intervenir, sino la inequidad en la distribución de la riqueza, su concreción desigual en el consumo material y simbólico. Esta idea se refuerza si, por anecdótico que parezca, nos detenemos a pensar sobre cuál es la dimensión cultural de la pobreza. Conocer la pobreza implica, más allá de las cifras galopantes, comprender el significado y la naturaleza del ultraje de la dignidad humana, poder medir el contenido de la cólera, de la impotencia, de quien está en tal situación y llega a sentirse de más en el mundo: el peso del coste familiar - la canasta básica, el techo de la vivienda, los zapatos del niño para la escuela si la tuviera, el casamiento si no el rapto-, la preparación para la muerte — no tener dónde ni con qué darle sepultura al padre-, la relación con otros grupos de una jerarquía y prestigio sociales mayores que ultrajan al negar el saludo u obviar la presencia, el comportamiento humilde para pedir trabajo o ayuda, el desespero por no tener que dar o brindar a los visitantes-huéspedes — ¡ni siquiera agua de café!_- El valor de una lectura cultural de la pobreza pasa por ayudar a reconocer la significación de factores estructurales que deterioran la dignidad humana como fuente social del amor propio y meta irreductible del desarrollo que se pretenda humano.

Al hablar de la cultura del desarrollo se reconoce que los agentes, consciente o inconscientemente, postulan una forma específica de cómo es el mundo, una cultura única homogénea y universal que no deja margen a duda sobre su validez ni se interroga por el punto de vista de los supuestos "beneficiarios". Así se niega la diversidad, se oculta o disimula una visión de las formas culturales del "pueblo" o la "comunidad" como premodernas, subsidiarias o marginales. La cultura practicada o común es descubierta por "los mediadores" que configuran o contribuyen a dibujar una imagen del "otro" a veces idealizada — "lo mejor" - y otras elitizada — "lo peor"-. Como advierten Grignon y Passeron (1991:15-54), generalmente se adoptan posiciones ilustradas o románticas en torno a las prácticas culturales en dependencia del protagonismo que se les da o el papel que se les confiere como propias de espectadores ingenuos o pasivos. Si los agentes caen en los extremos actúan como: populistas, en el sentido en que se cree en la autosuficiencia de la cultura otra, o miserabilistas, en el sentido en que se adoptan criterios de élite, se menosprecia o subestima al otro y, sencillamente, se adoptan posiciones paternalistas. Es fácil advertir la deriva entre posiciones etnocéntricas, relativistas o legitimistas en dependencia de la manera de entender a la cultura otra como una variable dependiente de políticas del interés institucional dominante. Para tener una idea mejor de este modelo en relación con los actores del desarrollo, pueden mencionarse dos situados en los últimos extremos como algunas ONG y el Estado. En cuanto a sus mentalidades, éstas muestran las formas dicotómicas de lo político cultural que se expresa con implicaciones político-ideológicas entre cultura de élite 
—_alta cultura" — y cultura popular — "cultura masiva" - De ese modo, la conciencia teorética o cientificista de los agentes del desarrollo puede padecer del etnocentrismo, común a ilustrados y románticos, que siempre oculta ideas racistas; del relativismo, cercano a la arbitrariedad y el autonomismo de los propios códigos y valores que conduce a posiciones populistas; o, por último, del legitimismo de unas relaciones de dominación con complejos sistemas de mecanismos y de efectos de jerarquización donde se manifiesta un marcado miserabilismo politico. Esta lógica cultural subyace en las formas discursivas sobre el desarrollo con las que se construye y representa la realidad dentro de un debilitado campo cultural, se sujeta a relaciones de dependencia con una élite — más o menos culta—, unas instituciones económicas y políticas metropolitanas, y se inmoviliza un descentramiento del sujeto y desprovee de su responsabilidad moral.

Reconocer la dimensión simbólica de la praxis desarrollista implicaría un ideal pedagógico de trabajo que promoviera desradicalizar estos extremos, descentrar la ambigüedad que supone el envés de la exigencia de nombrar en nombre de unas competencias culturales, proponer una articulación entre perspectivas - como arrepentimiento — sobre la base de una visión realista, no ajena, ni ingenua, al juego de creación de alteridades, para desplazarse entre las interacciones, en las zonas donde las narrativas se oponen y cruzan (García Canclini, 1997:59). Sólo en esos escenarios de tensión, encuentro y conflicto, es posible pasar de las narraciones sectoriales $-\mathrm{O}$, francamente, sectarias - a la producción de conocimientos capaces de deconstruir y controlar los condicionamientos de cada enunciación, las respuestas escasas en que se basan y la concepción fragmentada sobre el desarrollo que presuponen. Esto parece viable para los intelectuales dispuestos a emprender rupturas del double bind con las doxas de sentido común cotidiano y científico (Bourdieu, 1995:185); es decir, empeñados en un descentramiento de racionalidades que supere las unilateralizaciones y defina ámbitos de sutura entre las cuestiones de la verdad, la justicia y el gusto de cada uno - y de todosy los problemas epistemológicos, éticos y estéticos que dichas cuestiones suponen (Habermas, 1990:564). Mas, en la realidad, los prejuicios, estereotipos y creencias en que se fundamentan ciertas teorías que cotejan alguna evidencia empírica, parecen sobrevivir o “...desafiar el mundo fenoménico que se puede, en efecto, observar" (Sen, 2004:27).

Entonces, se impone subrayar que para desarrollar perspectivas alternativas en los esquemas interpretativos del desarrollo es necesario incluir la variable cultural de manera más explícita. Es decir, reconocer el papel de la cultura pero no de una forma reduccionista que vuelva sobre la consideración objetivista, míticosimbólica del desarrollo, sino sobre la necesaria y real autonomía de la cultura en un sentido amplio. Lo que quiero decir es que, en rígidos términos metodológicos, la cultura también es una variable independiente, o sea, que los procesos sociales se despliegan en el circuito de la lógica interna de la cultura. Si la cultura es social y pública como dice Geertz (1987), entonces lo social es un proceso cultural, un plano de expresión de ideas, de objetivación de vehículos o medios materiales y de realización de acciones constructivas cargadas de sentido. La cultura es constitutiva de todas las prácticas sociales; es social, porque es resultado y premisa de las interacciones, de los mutuos lazos de dependencia recíproca en los que participamos los hombres.

\section{...al desarrollo de la cultura}

Los interesados en el desarrollo social son, ante todo, mediadores y promotores culturales del impacto y los efectos de las formas discursivas de cualquier lucha política. Dichas formas, con sus contornos simbólicos, constituyen una episteme que reproduce la jerarquización asimétrica y la reificación con cargas morales, la 
naturalización de las relaciones sociales, su modulación vertical, unilateral, y hasta el talante repetitivo del pensamiento. Como se destacó antes, adoptar una posición de realismo permite ubicar tanto a los productos o creaciones "populares" —artesanía o música-como a las políticas culturales, en la lógica de las relaciones sociales, de las prácticas cotidianas en las que adquieren sentido y dentro de las cuales satisfacen determinada necesidad. El poder simbólico de los trabajadores culturales se juega al hacer ver, hacer creer y hacer existir las cosas (Bourdieu, 1993:148); es decir, cuando se plantean una mediación —-mediar, comprender, equilibrar - en las relaciones de poder y una promoción sociocultural de nuevas metas y consensos de calidad. Estas son dos tareas indiscutibles de suma importancia para los promotores y ejecutores de políticas de desarrollo porque en ellas se fijan sus posiciones inciertas y solidaridades. La intermediación es difícil, revela la ideología profesional o empresarial en nombre de la cual se opera. No necesariamente supone o se acompaña de un pensamiento crítico, cuestionador y abierto que asuma el desafío de unas relaciones de autoridad dadas y una vigilancia de actitudes salvacionistas, proféticas, mesiánicas o filantrópicas; sino más bien, todo lo contrario.

El trabajo de intervención y negociación se complica al reducir los imperativos culturales que afloran de las relaciones asimétricas, ahí se plantean verdaderos conflictos. Quizá se requiera siempre de, por lo menos: primero, legitimar la intermediación cultural del agente del cambio — ¿quién es?, ¿por qué ahí?, ¿para qué?, ¿para quién se trabaja? — y, segundo, hacer obligada la participación, la coproducción de todos los agentes nacionales o locales, los beneficiarios y las transnacionales (Mato apud. Yúdice, 2002:131). La participación o el involucramiento del "público" no implica una desprofesionalización de la intervención cultural, sino una propuesta que posibilitaría manejar la interacción social, arbitrar los conflictos y reconvertir las excentricidades de cada actor a partir de la complementariedad de miradas y las sinergias del trabajo colectivo. Cada individuo o grupo social tiene un capital cultural, unas competencias, recursos y hábitos que determinan sus interpretaciones del mundo y su quehacer en él. Se expresan en narrativas que son producto de la comunicación y la interacción en diferentes espacios de sociabilidad donde se manifiestan las aspiraciones y expectativas colectivas, las concepciones estéticas de la vida práctica. ${ }^{3}$ La cultura de hablar y la cultura de escuchar son valiosas para hacer posible la interacción que abre o cierra el desarrollo (Sen, 2004:26).

Cuando se plantea el problema de la capacidad de acción, cada proyecto requiere su propio análisis, seguimiento y evaluación de las variables socioculturales que lo afectan. Así, el estudio cultural y socioeconómico de factibilidad y evaluación de los resultados deberá visibilizar los incentivos culturales específicos que se necesitan para obtener la participación local. Por razones como ésta, el desarrollo es ante todo una tarea cultural que puede acompañarse a través de un trabajo científico. Pero en esta idea la cultura no debe ser solamente una variable concreta como en el enfoque clásico, ni, como en muchos casos, una variable de la alta cultura y del sistema institucional. De hecho, así lo demuestra el interés por la cultura de los gobiernos y de las fundaciones como medio instrumental para nivelar las desigualdades, "habilitar" o proporcionar capacitación a las comunidades. Esta acción simbólica del entramado institucional y de los filántropos de la cultura determina las posibilidades para comprender satisfactoriamente las dinámicas sociales y reconocer que los procesos sociales se despliegan en la lógica de la cultura (Alexander, 2000:2).

Si se miden los indicadores de marginación de la cultura por el gasto en programas culturales o en investigación, se tomará un indicador engañoso. Seguramente se constatará una alta inversión que no 
habla de cómo la cultura es marginal en relación con otros sectores considerados centrales por su utilidad económica o "estratégica". No obstante, ese no es el principal peligro de las visiones economicistas, librecambistas. Un economista clásico diría, casi siempre, que los errores en los programas de desarrollo brotaron de análisis económicos equívocos más que por la falta de perspectiva cultural; un neoliberal ni siquiera se plantea este problema porque tiene claro que su receta económica se fundamenta en la regulación del déficit fiscal, el control del gasto y la eficiencia garantizada por la competencia y la liberalización. Las afirmaciones sobre la falibilidad económica de los proyectos culturales nacen de una visión de la economía ajena a perspectivas antropológicas y sociológicas, al insistir en una esfera separada del sistema sociocultural, las redes de relaciones sociales de producción, intercambio y consumo. Ahora bien, ¿qué indicadores pueden dar cuenta del desarrollo culturalmente sustentable?

Generalmente, se suele poner el acento en los factores técnico-financieros u otros indicadores económicos, que padecen de igual "cuantofrenia" — como el número de empleos - o profesionales — valores institucionales o estéticos-, mientras que se desatienden las cuestiones ético-democráticas relativas a la justicia social, o se reducen éstas a partir de criterios de utilidad como medio de legitimar la inversión en capital humano, social o cultural. De hecho, cuando se recomienda invertir en educación, no queda claro en qué educación se supone se deba invertir: en la pública o en la privada; en la pedagogía vertical y repetitiva, con la instrucción de un conocimiento instrumental; o en una educación analítica, sintética, que desarrolle el pensamiento crítico y la independencia intelectual de cada individuo preparándolo para discernir y construir su punto de vista. Al discutir sobre cultura y desarrollo surge, frecuentemente, esta cuestión de la relación entre los factores culturales y la evaluación del éxito de los proyectos. Se trata del contraste entre evaluación cuantitativa en términos financieros y evaluación cualitativa en términos de impacto cultural. No olvidemos que un efecto positivo en el crecimiento económico se puede acompañar de francos retrocesos en la calidad de vida. En este sentido es necesario hacer una codificación de la dimensión cultural que sea independiente de las tasas de rendimiento económico que, obviamente, no se pueden soslayar. No obstante, tales criterios de eficacia como parte de la administración de la cultura, deben quedar sujetos tanto a criterios económicos como a cívicos, sociales y educativos.

Superado el dogma de la cantidad hechizada, el verdadero rendimiento social de la inversión en el desarrollo cultural pasa porque dicho desarrollo es, también, susceptible de transformarse en un valor de mercado. En este sentido, hay que insistir en que "la atención a la cultura rinde económicamente" (Kottap, 2000:104; Yúdice, 2002). La tasa de rendimiento en proyectos culturalmente compatibles es muy superior a los que no lo son. La cultura como clave utilitaria de los desarrollos urbanos evidencia que es un recurso medular del desarrollo contemporáneo en dos direcciones: la elevación de la calidad de vida y el crecimiento económico. Por ello los proyectos de las ciudades postindustriales buscan estimular los servicios como sector productivo y atraer capitales al promover entornos creativos para las nuevas industrias del conocimiento. Por ejemplo, las apuestas de Bilbao, Lyon, y Río de Janeiro y Guadalajara por concesiones del Guggenheim persiguen, con el museo de arte, promover la revitalización del desarrollo urbano y el turismo cultural. Así estas grandes ciudades que tratan de resolver sus dificultades para dar servicios a la ciudadanía y ganar en competitividad regional, procuran conseguirlo al generar un amplio movimiento entre actores diversos que asumen como meta colectiva el desarrollo de unas infraestructuras culturales capaces de reestructurar los espacios de encuentro colectivo, re-urbanizar la vida cotidiana y usar más la ciudad con 
fines turísticos como una experiencia cultural. Sin embargo, las iniciativas de preservar la identidad cultural, proteger el patrimonio cultural y natural, gestionar los recursos, permanecen amenazadas ante la liberalización por la que presionan las industrias culturales transnacionales que perciben en muchas de esas políticas "trabas al comercio."

En este sentido también son atractivos los modestos museos comunitarios si movilizan recursos, no tanto la alta cultura artística, sino la cocina, las costumbres, los rituales y otros repertorios simbólicos aunados a las prácticas cotidianas que constituyen los patrimonios culturales locales. Ello supondría, por parte de las instituciones culturales, una mirada antropológica de la constitución de las culturas cotidianas y la valoración estética de las obras sin exotizar su identidad, para constituir mercados y circuitos paralelos de la cultura donde se valoricen los productos culturales y, también, se sienta valioso el público involucrado, atraído o "producido". Éstas son apuestas a la gestión del patrimonio, a la administración y al uso sustentable de los recursos, conocimientos, tecnologías, también a sus riesgos. La gerencialidad de la cultura es la encargada de localizar los intercambios materiales y simbólicos más allá de la institucionalización del discurso.

Los estudios socioantropológicos de la dimensión cultural del cambio social enfatizan, entre otros, que la meta de la estabilidad es el principal empuje para el cambio (Kottap, 2000:105). A partir de los avances de la paleontología se insiste en que la evolución se da cuando los sistemas que están cambiando paulatina y progresivamente tratan de mantenerse como ellos mismos al tiempo que cambian gradualmente. Los "beneficiarios" del desarrollo desean cambiar estrictamente lo suficiente para mantener lo que tienen por poco que sea o parezca. Aunque la gente quiere algunos cambios, su cultura tradicional y las pequeñas preocupaciones cotidianas son las que proveen los motivos para modificar su conducta. Sus valores culturales no son necesariamente los abstractos "valores de los planificadores"; más bien, tienen objetivos específicos, definidos con los pies en la tierra, objetivos como mantener los rendimientos de maíz o arroz, acumular recursos para una ceremonia, conseguir que el niño sobreviva al primer año de vida y que más o menos nutrido empiece, vaya, o termine la escuela mientras trabaja para apoyar la economía familiar. Es decir, que más que pensar en continuidades y rupturas, se trata de formular propuestas que enmarquen los momentos de las escisiones entre pasado y futuro, tradición e innovación, en los procesos de actualización de las identidades con que los sujetos dan coherencia, totalizan y reflexionan sus experiencias de vida, es decir, luchan por su identidad social.

Los proyectos realistas y viables promueven cambios, pero no sobre innovaciones. La meta de "cambiar para mantener" estaba implícita en todos los proyectos exitosos del BM que examinó Kottak hace unos años; ello implica preservar los sistemas haciéndolos funcionar mejor. Los proyectos efectivos respetaban los patrones de la cultura local o, al menos, no se oponían a ellos con representaciones que reproducen narrativas colonialistas para justificar la innovación académica, científica o tecnológica. Los campos de acción no se construyen sin la centralidad de la memoria y la actualidad contradictoria del pasado. En este sentido, se puede hacer uso del potencial de aprendizaje del que culturalmente se dispone o, en otras palabras, de la capacidad de aprender a aprender. El presente es siempre combinación de productos heredados y de efectos innovadores con improntas de futuro. La verdadera identidad por la que luchan los sujetos es la de la actualización de sus repertorios de acción para seguir habitando el mundo que les toca vivir.

En resumen, la cultura adquiere una importancia decisiva como concepción general para la transformación de la realidad y para el desarrollo humano. No se puede hablar de un desarrollo social 
real, efectivo y perdurable si no está dimensionado culturalmente. El desarrollo cultural implica por una parte, que no se impongan patrones arropados de supuesta superioridad que son ajenos a los grupos - a veces se piensa por otra gente y se imponen necesidades propias sin tener en cuenta las ajenas, las reales del otroque se conozca primero por qué la gente actúa como actúa, hace lo que hace y piensa como piensa. Como dice el economista cubano Julio Carranza, el hombre es lo que es y de él hay que partir, porque desconocerlo sería caer en el idealismo (1999:35,37). Aunque esta incitación introduce cierta dosis de escepticismo sobre la condición humana, también se trata de destruir falsas ilusiones, no sólo imposturas y voluntarismos irresponsables, no sólo fatalismos. De alguna manera es un realismo al que el pensamiento contemporáneo no puede darse el lujo de renunciar, pues apuesta por conectar lo existente y lo probable con lo posible.

Por otra parte, al descubrir las especificidades y potencialidades de cada hombre o grupo social y trazar estrategias que promuevan lo nuevo, se le devuelve vitalidad como actor de los procesos de cambio a partir de su decisión sobre qué cambiar de la tradición compartida, qué revitalizar y cómo. A veces se exige o induce a que el "pueblo" o "la comunidad" se comporte de acuerdo con la imagen que de él o ella nos hemos forjado como mediadores, y nos olvidamos de lo que realmente quieren o necesitan; además esto guarda estrecha relación con el impulso a atribuir la falta de desarrollo a los demás. De todas formas, siempre se realiza una mediación asumiendo los términos y procedimientos del ideal cultural que se comparte y elige para una sociedad. Renunciar o negar ese ideal es imposible o, por lo menos, bastante hipócrita. Se trata más bien de lo opuesto: de mantener ideales pero, al mismo tiempo, de respetar, conocer, comprender e interpretar a los actores sociales para poder encauzar el potencial emancipatorio y la conciencia crítica de todos como agentes de cambio.
Es difícil renunciar a cierta dosis de utopismo crítico, lo que de ninguna manera supone ser un sujeto delirante de la acción política (García Canclini, 1997:60). El ser humano puede y debe ser otro mejor.

\section{Excurso: las políticas culturales, anclaje y fuga}

A estas alturas son evidentes algunos aspectos de la relación entre cultura y política, aunque aún se requiera avanzar más en la comprensión de la arista tratada aquí. Como apuntamos al inicio de este ensayo, en la medida en que la sociedad capitalista contemporánea es una sociedad de la cultura, la lógica cultural se encuentra en el centro mismo de su (re)producción simbólica y material. Por tanto, su control es un ámbito de anclaje tanto de las relaciones de poder, que sabemos son siempre de dominación, y los procesos macroeconómicos; como de las preocupaciones del campo intelectual y, en consecuencia, de los análisis culturales de la sociedad, las subjetividades y los conflictos emergentes alrededor de nuevas formas de reproducción de la cultura, la integración social y la socialización de los públicos (Inglehart, 1991). También, de las simulaciones culturales - ficciones - de las relaciones sociales y comunitarias porque, como dice Yúdice: “... El recurso de la cultura sustenta la performatividad en cuanto lógica fundamental de la vida social hoy" (2002:43). Por ello, la cultura del desarrollo está relacionada con el desarrollo de la cultura no sólo como ámbito de anclaje, sino como ámbito de fuga para un desarrollo con humanización y racionalidad ecológica aunque para demostrarlo se subrayen las "ganancias indirectas".

Sin dudas, la cultura rinde como discurso y como recurso desde los puntos de vista político y económico (Kottap, 2000:104; Yúdice, 2002). Si tenemos en cuenta que la cultura como recurso, en una concepción expandida, sirve para negociar problemas, promover 
pautas de confianza, cooperación, articular el consenso social, favorecer la interacción social e impulsar un desarrollo vigoroso con crecimiento socioeconómico, eficacia democrática y calidad de vida; entonces, el análisis, el fortalecimiento y la promoción de la cultura, se convierten en una forma de hacer política, de instrumentalizar las metas del desarrollo social y humano y aplicar los resultados de las investigaciones de la cultura. Empero, la política puede sobredeterminar in extremis la cultura hasta politizar las prácticas culturales y provocar escaladas conflictivas. Las políticas culturales se encargan de modular las desigualdades socioculturales como medio para mejorar la calidad de vida de las colectividades y para la realización digna del hombre. Es decir, modulan y constituyen la provisión y distribución desigual de bienes y servicios culturales.

En este sentido se orienta el primer objetivo recomendado por la Conferencia sobre Políticas Culturales de la UNESCO (1998) a los países miembros: convertir las políticas culturales en uno de los componentes clave de las estrategias de desarrollo. Las políticas culturales constituyen una respuesta al reto que plantea la sociedad moderna de integración social, de articular el consenso social alrededor de renovados valores sociales y de producir sujetos o ciudadanos ideales — productivos, éticos, responsables-. Como conjunto de intervenciones para mejorar la calidad de vida de las colectividades, el impulso de la dimensión cultural basada en la igualdad, la democracia y la mejora de condiciones de vida (García Canclini, 1987:26) las políticas culturales forman una plataforma de exigencia para la exaltación de la dignidad individual, los valores espirituales, los derechos sociales, políticos, civiles y culturales. Ellas pueden promover (o no) la innovación social fomentando (o no) el desarrollo de actividades socioculturales tradicionales o nuevas que permitan una participación activa en la vida cultural. Por último, no puede obviarse que las actividades culturales constituyen y promueven fuentes de empleo, ya que las iniciativas demandan mano de obra; tener un trabajo supone un capital social, una red de relaciones que reduce la vulnerabilidad social, la exclusión o la marginalidad social (Castel, 1997).

Desde un plano más teórico, se puede entender a las políticas culturales como vehículos de producción y difusión de las formas de saber, de los códigos de representación y los procesos de apropiación y definición de la realidad. En estos términos, se subraya el hechizo que las envuelve pues no dejan de constituir soportes culturales para la legitimación del poder y la dominación; mientras, el gestor cultural se debate en resolver con congruencia las difíciles cuestiones sociopolíticas, económicas, éticas y estéticas que su actividad implica. Las políticas culturales son fuerzas moduladoras de las sinergias que contribuyen a la creación de una realidad acorde con los intereses de la colectividad, y a fijar las pautas de la distribución y el acceso a los bienes y servicios culturales. Por ello, pueden entenderse como procesos sociales de distribución de poder a través de un conjunto de estrategias o líneas de actuación de grupos de trabajadores de la cultura, las instituciones y el Estado.

Las políticas culturales tienen el reto de articular la mayor productividad de bienes culturales, el desarrollo de los medios de expresión y la aportación crítica hacia los productos culturales, es decir, pautar su suerte social durante la comercialización y el consumo de estos productos. Las visiones en conflicto sobre el rol de las políticas culturales parten del concepto de cultura sobre la base que se diseñan, a saber: un "servicio público"o un "bien colectivo". Estas concepciones se traducen, por ejemplo, en la prioridad que se le confiere a los equipamientos de formación o de socialización respectivamente. Cuando se parte de la cultura como un servicio público, se pone énfasis en la programación o planificación de actividades educativas o ferias y festivales, o sea, que ciertos departamentos administrativos dirigen la oferta cultural al establecer sus contenidos y 
temporalidad. Mientras que cuando se parte de la cultura como un bien público se enfatiza en la libre capacidad de los actores sociales para satisfacer sus exigencias y demandas en espacios de libre encuentro y realización. ¿Cómo y qué espacios se facilitan para servir o socializar la cultura? ¿Quién y cómo decide el menú de dicha carta? Este es el encargo de los políticos de la cultura aunque, generalmente, lo olvidan en la medida en que el Estado deja de construir su hegemonía sobre la base del bien común y recibe con beneplácito que la iniciativa privada se ocupe de proveer bienes y servicios culturales con un impacto negativo en el plano de la justicia social. En esta paradoja se esconden las perversiones y patetismos de las políticas culturales.

Ambas concepciones y sus consecuencias prácticas son estrechas, parciales, y limitadas. La primera presupone lo que la gente quiere, pauta un "deber ser" ajeno a sus necesidades reales y gustos, aun cuando parte de posiciones colectivistas que pretenden igualar el consumo cultural a partir de un acceso a los servicios igualitario o equitativo. La segunda es usada como justificación para el des-comprometimiento de las instituciones públicas con la distribución equitativa, promueve posiciones individualistas bajo el supuesto que de ello se encarguen los innovadores de la sociedad civil local al ampliar la libertad de elección del consumidor — soberano pero controlado, clasificado y jerarquizado - y responde a sus demandas reales. No en balde esta última posición es la promovida y cómoda para el neoliberalismo; mientras que la otra, sitúa un estatismo inocuo que puede rozar el totalitarismo bajo un rostro paternalistamente filantrópico o un mecenazgo cautivador. Sin embargo, ambas concepciones no son excluyentes y pueden complementarse. El ideal podría ser mantener un fuerte compromiso público con la equidad y la participación, al promover un contexto institucional que estructure la vida pública — prácticas, normas y metas-y, al mismo tiempo, proveer los medios de expresión y realización de las personas para actualizar sus identidades individuales, grupales y comunitarias por medio de la experiencia pública donde la iniciativa privada pueda expandirse con responsabilidad social.

El modelo empresarial de la dinámica económica del capitalismo tardío rige la lógica social y, en particular, del campo cultural y de la producción de conocimientos. Esto se constata en las industrias del copyright — del libro, la música, la prensa, la TV-, en los procesos de comunicación masiva que es donde se desenvuelven las principales actividades culturales tanto relativas a la presentación de los productos y en la constitución de sus públicos consumidores — marketing y publicidad—, como en las formas de producción mismas. Las industrias culturales tienen y tendrán un papel fundamental en la dinámica de la nueva economía cultural basada en un nuevo paradigma tecnológico (Castells, 1995), en los cambios en los vínculos socioculturales y en las demandas de las sociedades contemporáneas. La economía cultural no deja de ser política (Yúdice, 2002:31). Hopenhayn (2001) afirma que estas industrias se han convertido en un espacio significativo de disputa por la articulación de la cultura y la política, se entiende que en la actualidad no es tanto en la producción de sentido sino en su circulación donde se juegan proyectos políticos: “...en la circulación, mucho más que en la producción, la cultura deviene política" (69-89). En la modernidad, la presencia mediática, en cuanto articuladores sociales emergentes, ha sido central en la construcción y el ejercicio de una ciudadanía regulada por la fuerza estética de los mensajes presentados por sus profesionales de la intermediación cultural acrítica, a saber: los periodistas. El desarrollo tecnológico y la demanda de procesamiento de información seguirán favoreciendo ese protagonismo cuya contracara puede reforzar las grandes asimetrías de poder simbólico. "Dar vida a un lugar" y, sobre todo, a las ciudades, como dice Castells, es parte del nuevo panorama que se presenta a las políticas culturales. 
Pensar el problema de proponer políticas culturales plausibles con las transformaciones de las relaciones sociales, implica aclarar los vínculos de las políticas con los efectos del modelo neoliberal, el modo que la globalización cultural ha adoptado en cada territorio -producción, distribución, circulación y consumo cultural-, así como las formas institucionales que asume la hegemonía y la resistencia cultural. La plausibilidad de las políticas culturales presupone un análisis cultural de la sociedad (Wortman, 2001:251).

Se ha insistido en que la administración y gestión de proyectos culturales, así como la programación de agendas culturales, deben ser pertinentes culturalmente hablando, es decir, que deben ajustarse a las necesidades estéticas y prácticas a las demandas de las poblaciones, al tiempo que no renuncien a la promoción de nuevos valores. La sustentabilidad de los proyectos culturales depende, entre otros factores, de esos valores que promuevan, las rentas que exijan, los empleos que generen, los niveles de participación que alcancen y la capacidad de gerencia y gestión cultural. No obstante, infinidad de proyectos dependen del apoyo oficial o de la ayuda financiera privada, pero: cla creatividad cultural está reñida con equivalencia económica y la correspondencia política que alcance? No, aunque sí está sometida a sus rejuegos. La suerte de muchos proyectos innovadores pasa porque puedan arrancar con un apoyo inicial o incentivos públicos locales legales o económicos, a veces hasta emotivos-, para luego consolidarse con éxito y rentabilidad. Curiosamente su viabilidad, en caso de consumarse, parece un problema para los políticos que no invierten porque, las más de las veces, el activismo cultural innovador proviene de movimientos cívicos u ONG progresistas que han apostado por la cultura entendiéndola de distintas maneras (Yúdice, 2002:18).

Es necesario imaginar formas asequibles de gestión, distribución y consumo de las actividades artísticas y culturales. Todo este trabajo inmaterial añade valor a los bienes, fomenta la inversión y el desarrollo comunitario. ${ }^{4}$ Las alternativas en la circulación a partir de las redes de servicios para promover relaciones donde se produzca cultura, se comercialice y se encuentren los creadores —aficionados y profesionales-, favorece dicha producción de bienes y la expresión de las culturas vivas. De cualquier manera, las acciones de las redes comunitarias no constituyen una compensación a la avalancha de la iniciativa privada ni a la "capitulación" del Estado. Hoy los gobiernos se concentran, fundamentalmente, en patrocinar festivales, ferias culturales o megaeventos espectaculares. Estos son parte de agendas culturales que contribuyen a diversificar el gusto, fomentar las relaciones sociales, la colaboración y la seguridad del entorno, pero se requiere investigar su impacto y hasta qué punto su carácter anual limita el alcance de sus metas, si los logros se adecuan al gasto que suponen y si el público se ve representado y entusiasmado o no.

Los estudios culturales pueden contribuir al análisis de la significación e impacto de las políticas, con la evaluación del correlato entre oferta y demanda, entre los ideales deseados y las prácticas reales. También, dando cuenta de las nuevas formas de producción de la cultura, de los productos culturales y de sus públicos. En cuestión, se trata de constatar las formas en que se articulan los actores y sus ámbitos principales: los productores culturales — sobre todo, agentes de la creación-, el entrado institucional y las burocracias públicas que regulan los mercados culturales y los grupos de consumidores, es decir, las audiencias con sus microdinámicas específicas. Las políticas culturales deben ser analizadas con una visión holística que dé cuenta de los múltiples aspectos que intervienen tanto en la planificación, la implementación, la ejecución y sus impactos. Así algunos aspectos analíticos para dar constancia de las permanencias y rupturas pueden abordarse al responder preguntas tales como: ¿dónde se interviene?, ¿para qué se interviene?, ¿por qué se 
interviene?, ¿quiénes son responsables?, ¿con qué medios o instrumentos cuentan?, ¿a quién se favorece?, ¿qué hace la intervención?, ¿qué logra la misma? Al analizar las políticas en todas sus fases, no se puede perder de vista que intervienen una pluralidad de actores — productores, instituciones y consumidores — cuyos modos de relacionarse determinan la complejidad y las contradicciones de los procesos. En este sentido, es pertinente seguir esas dinámicas teniendo en cuenta cómo se vinculan los distintos sectores sociales - mercado, estado, comunidad y familia- en la provisión de recursos y bienes, y los procedimientos o procesos que devienen definiendo en la práctica la lógica de todas las relaciones sociales — estatalización, mercantilización, comunicatización o familiarización (Adelantado, 2000:23-61).

Un problema central para el análisis cultural es dar cuenta de la escisión entre el ideal discursivo — qué se proyecta, desea o debe hacer-y las prácticas reales — modo concreto de aplicación de lo que se pensó o se planificó_- Como se sabe, los problemas de la práctica siempre rebasan los límites del pensamiento. Dar cuenta de esas diferencias entre ofertas y demandas es una tarea de los análisis de las políticas culturales. Los estudios culturales pueden servir para explicar y comprender aquello del pasado que impide o puede favorecer en el presente un desarrollo, un desenvolvimiento más cabal, más pleno y, además, para ayudar a los actores sociales a re-conocer sus verdaderas capacidades creadoras, a procurar su realización cultural y social. También, evaluar los ejes de desigualdad que operan transversalmente en la esfera cultural, a saber: desigualdades de clase, género, etnia o edad, de ciudadanía — sujeto de derechos-, diferencias de posiciones respecto a la estructura administrativa del estado — clientes o no de las burocracias públicas, empleados o beneficiarios de los servicios sociales — desigualdad de capacidades asociativas —esfera relacional y distintas esferas de acción_- Las políticas culturales pueden impulsar la democratización y la socialización al favorecer la multiplicación de los actores; el reconocimiento de sus voces, al ponerse al servicio del bienestar; la felicidad colectiva, al producir bienes y riqueza directa $\mathrm{o}$ indirectamente.

Los estudios recientes tienden a contemplar al conjunto de intervenciones realizadas por el estado, las instituciones civiles y los grupos comunitarios organizados con el fin de orientar el desarrollo, potenciar la creatividad, satisfacer las necesidades culturales de la población y obtener consenso para un tipo de orden o de transformación social. El análisis de las políticas culturales puede dar cuenta de los problemas identitarios y de las oportunidades, las proyecciones y peligros de la convivencia en la heterogeneidad social. Quizá la contribución mayor pasa por indicar cómo aprovechar la heterogeneidad y la variedad de mensajes disponibles y aprender a convivir con los otros (García Canclini, 2000); o, como le dijo un shuar de Ecuador a connotados museólogos conservacionistas en una reunión en EUA: “...lo que en rigor se necesita es documentar la cultura para el desarrollo cultural de la comunidad" (apud. Yúdice, 2002:130).

No se puede dejar de subrayar que en medio del impacto de las políticas neoliberales en la crisis de los lazos sociales, se evidenciaron los límites del estado benefactor y se muestra la incapacidad del estado privatizador — incluso de la vida y la muerte — para una autocrítica que permita desplegar una fase éticopolítica. Fase donde sus estructuras más o menos maduras, potencien la conversión del Estado en un agente de reformas culturales, más allá del corporativismo y la economía librecambista, maquiladora, que propone la ética de la cultura consumista como clave para la configuración de identidades y el desarrollo económico. En otras palabras, que el poder estatal apueste no sólo por el 
componente económico al legitimar su hegemonía, sino también por el componente ético cultural para desarrollar su tradicional tarea de "disciplinar" el cuerpo y "neutralizar" la mente, pero sobre la base de una ciudadanía cultural, de una democracia inclusiva y una práctica reflexiva. Los poderes existentes requieren emprender tal tarea, mas su capacidad está en duda si se tiene en cuenta que lo que está en juego es la naturaleza de su poder y de los actores dominantes que le exigen, por ejemplo, vigile todo lo que se opone al régimen de apropiación de la cultura que ellos controlan. No obstante, el estado neoliberal al reducir la subvención a los servicios, en medio de la desconfianza creciente que en su conjunto le ha tenido la sociedad, abrió la brecha y habilitó a múltiples actores, y entre ellos los de la sociedad civil, para que actuaran y definieran una alternativa constructivista de desarrollo cultural que no necesariamente reduce o privatiza lo social y lo cultural frente a cualquier desencanto.

Las industrias culturales, a través de sus fundaciones, sustituyen al estado con sus subsidios cuando éste reduce los presupuestos destinados a cultura y promueve la descentralización de las políticas culturales nacionales. Los gobiernos provocaron con sus políticas de desregulación y su endeudamiento, que el apoyo cultural recayera en asociaciones públicas-privadas, corporaciones semiprivadas y paraestatales devenidas de poderosos intermediarios en la financiación. La política cultural estatal descuida la producción, la circulación y la recepción de los productos culturales. Tal es el caso del Estado mexicano cuya política no expresa a cabalidad ni potencia con fuerza el trabajo creativo y de la comunicación, a pesar de su importancia para la economía del país pues aporta al PIB $7 \%$ aproximadamente (Piedras, 2004:181).

Planear, administrar y financiar la cultura en un marco neoliberal donde Estado, mercado y sociedad civil se combinan, replantea el problema de la agencia cultural. Si el correlato entre globalización y cultura ha redefinido convenientemente la segunda para establecer con ellas relaciones de conveniencia, adecuación o pertinencia a favor del "imperialismo cultural" de occidente (Yúdice, 2002:44-45), entonces se debe celebrar con prudencia el papel de la agencia cultural en espacios formales o informales, oficiales o alternativos, públicos o privados en relación con la voluntad de las agrupaciones de artistas y los entramados institucionales de administración de la cultura. El trabajo cultural está preformado por la lógica de los distintos actores que, a través de unas redes más o menos densas, actúan en nombre del estatuto cultural de cada uno, mientras se enfrentan al desafío del reconocimiento de los otros. En el juego de relaciones recíprocas donde se construyen y representan las identidades, dicho estatuto proviene de la red de conexiones que neutraliza las posibles ventajas, regula la identidad y protege de la arbitrariedad. Todo ello mientras que: la creatividad del público no cesa porque hacer cultura es una forma de vida, el Estado hace poco para contrarrestar la destrucción de cualquier forma de diversidad, y las trasnacionales con sus lobbys exigen mayor conectividad liberalizada.

Es cierto que las culturas locales y regionales están planteando demandas, es más: “...Hay una demanda de ser actor cultural" (Wortman: 2001:261). El imperativo de descentralizar así como de democratizar la cultura condujo a aumentar las demandas de inclusión y pertinencia de la comunidad, que algunos consideran un medio de dar poder y otros, de cooptación política. De ello dan cuenta los cambios en los espacios públicos a constatar en la proliferación de cibercafés, los bares culturales, multicines, megamuestras de arte barrial, las escuelas o talleres de danza y las presentaciones callejeras de música o teatro; además, los usos invisibles o underground de Internet, del cable, los videos, televisiones y radios, del tráfico o la piratería que alcanzan una complejidad inusitada en las urbes. Esta emergente diversidad de prácticas y vínculos comunitarios expresa la vitalidad de las formas de sociabilidad locales a través 
de acciones culturales, de nuevas formas de consumo y de ciudadanía activa (Calderón y Szmukler, 2004). En este sentido, los problemas de la discontinuidad cultural no están superados por la globalización, por los nuevos universales que ésta impone como formas de incorporar y homogeneizar desigual, jerárquica y asimétricamente. ¿Cómo hacer convergente o conmensurable la heterogeneidad y volverla productiva?

Los marcos de entendimiento, interpretación y conducta producidos en las sinergias entre actores como redes establecidas o rearticuladas con la ayuda de organizaciones de la sociedad civil, convierten a lo cultural en un área cuyo dinamismo potencia la negociación y la lucha para desarrollar un ethos democrático a partir de expandir la esfera pública (Willis, 1999; Calderón y Szmukler, 2004). De hecho, ellas promueven una mentalidad de red, como estructura flexible de producción, distribución, promoción, circulación y consumo. El estatuto de las redes dependerá de quiénes participan de la red, a quiénes se invita, para descentralizar los paradigmas o modelos de cada uno y para desarrollar una visión mejor de uno mismo y una realización personal distinta.

El nuevo paradigma de la acción cultural que se plantee un sentido democrático en los planes estratégicos de desarrollo social requiere un ethos humanista y una educación o alfabetización crítica. También, replantear la problemática autonomía del campo cultural en relación con las instituciones del Estado, del mercado y de la sociedad civil transnacional. Ahora bien, el mismo Estado está atrapado en discusiones cruciales para la identidad cultural entre esos intereses transnacionales y los locales, entre las redes articuladas en nombre de la acumulación según la lógica del mercado de valores competitivos y excluyentes, $y$ las redes que promueven la solidaridad y el sentido de pertenencia. Los contrapuntos en torno a si los productos culturales no deben estar sujetos a términos comerciales —entendiéndolos como herencias que forman parte del patrimonio- o constituyen mercancías como todas las demás, plantean un verdadero problema de soberanía. ¿Cómo se va a resolver el problema de la soberanía si el Estado se desplaza dejando el juego abierto y con reglas mínimas? ¿Puede realmente el mercado garantizar los derechos civiles, sociales y culturales, y la calidad de vida?

La cultura importa, pero privatizar, reducir y descentralizar el sector público en lo tocante a las políticas culturales, supone para la discusión sobre la soberanía cultural una reducción del carácter nacional de las producciones estéticas o, para decirlo de otra manera, un paso del "made" al "assembled" o al "imported by". Antes, la cuestión de orden era proteger e impulsar una producción endógena que permitiera cuotas de programación reducidas para las importaciones (García Canclini, 1999); ahora, las tendencias de protección nacionalista pasan a ser regionales o continentales. Esta tendencia ha impulsado la discusión sobre el papel de las culturas regionales frente a la inminente ruina de las industrias culturales nacionales, la reorganización mercantil del intercambio de bienes culturales en función de reconsiderar sus beneficios arancelarios e impositivos como en el caso de los libros-, y el desequilibrio comercial por el desmesurado poder audiovisual de EUA, quien monopoliza la programación en las redes y en los sistemas satelitales y de cable latinoamericanos y europeos (Yúdice, 2002:228). Sin embargo, la integración del continente se está llevando a cabo en los términos estipulados por las corporaciones estadounidenses y transnacionales, es decir, a expensas de los países latinoamericanos y favoreciendo el "bombardeo cultural" o la "americanización" en la medida en que la producción de bienes y el consumo, en relación con los salarios de miseria de nuestros países, están de capa caída (García Canclini, 1999; Getino, 2003; Yúdice, 2002:322). Esto actualiza la necesidad de ensayar políticas innovadoras para regular los mercados regionales de bienes culturales y de sistemas más eficaces de intermediación cultural no 
sólo en la producción, la circulación y el consumo, sino en el aprendizaje de las interrelaciones culturales. ${ }^{5}$

El debate entre el desplazamiento de las empresas y la localización de las poblaciones y lo social fragmentado (García Canclini, 2000), plantea ¿cómo rearticular formas de solidaridad en tejidos sociales deshechos culturalmente? Para ello adquieren sentido las políticas culturales, como instrumentos imprescindibles para repensar los acuerdos colectivos, los pactos sociales. Sin embargo, el poder de las políticas culturales debe ser cuestionado pues pueden constituir y modular las desigualdades culturales pero difícilmente rebasarlas de un tajo. El uso de la cultura para suavizar heridas de conflictos, nivelar escisiones sociales puede, al mismo tiempo, exacerbar o perpetuar las asimetrías en la distribución del capital cultural y las jerarquías. El panorama es sombrío porque todo indica que esas desigualdades se agudizarán con la impotencia de un Estado atado de pies y manos, incapacitado por instrumentos internacionales y por miedo a innovar para garantizar la igualdad entre culturas diferentes.

El abandono de la capacidad regulatoria del Estado no significa debilidad de su capacidad de cooptación aunque se haga más vulnerable. Puede re-emerger como un intermediador privilegiado alimentando la fantasía de una recíproca cultura común y de la diversidad cultural. Estas dos retóricas desempeñan un importante papel al consolidar a los grupos susceptibles de ser capitalizados por las instituciones académicas, artísticas, mediáticas y del mercado. Un problema del discurso multiculturalista adoptado por el estado para manejar la diversidad tradicional y emergente consiste en que no lo deje en manos de expertos tecnoburócratas al resignificar lo nacional y promover una sociedad más igualitaria. La cuestión de la revalorización de las identidades culturales desterritorializadas no deja de ser un objetivo de las políticas culturales en Latinoamérica, cuando éstas asumen nuevas complejidades y recrean el sentido de lo colectivo intra e interregionalmente.
El desarrollo del capital cultural requiere democratizar la vida económica y política, compartir o luchar por el control de los medios de simbolización de las instituciones estatales que afirman sus derechos de propiedad y de crear espacios para las culturas locales, redes de países para colaborar, aprovechar potencial humano e institucional, desarrollar programaciones conjuntas, intercambios culturales entre pueblos, así como de respuestas creativas y una organización de la gestión más fluida e informal. Todo ello en medio de una llamada a revalorizar la diferencia local dentro de los circuitos globales, y el reto de la integración cultural como principal motor de la actividad y la acumulación de capital (Yúdice, 2002:323). En síntesis, orientarse hacia nuevos sentidos de los derechos sociales, es decir, a la ampliación de la idea de ciudadanía a partir de políticas de reconocimiento basadas en una ética transcultural y sustentadas en normativas de convivencia multiculturales y supranacionales (García Canclini, 1997:50).

Más que proponer diversas políticas en diferentes esferas o sectores, una política de la cultura del desarrollo tendría que articularse con la política educativa y con todas las políticas sociales. En fin, se trata de políticas ciudadanas inclusivas, democráticas — participativasy multiculturales, capaces de ocuparse de la totalidad social, coadyuvar en el desarrollo como imperativo de sobrevivencia al sumarse a los actuales procesos de estetización de la vida cotidiana - liderados por los media-, canalizar, facilitar y generar procesos de estilización de la vida de los trabajadores de la cultura y, en general, de todos los que viven las culturas.

Los criterios de habitabilidad de la nueva política pueden definirse al enfrentar los peligros que suponen el monopolio de los centros hegemónicos, la interdependencia asimétrica, la constitución híbrida de los sujetos a partir de nuevos consumos culturales y estilos de vida, la transformación de ciertos grupos en minorías y su incorporación subordinada, el sometimiento a los 
imperativos del mercado - lo que no es sinónimo de exclusión de industrias culturales-. También, a la necesidad de producir plusvalía simbólica a través de manifestaciones culturales que den placer, disfrute y entusiasmen, que den sentido a la heterogeneidad al reconocer su polisemia y heteroglosia.

La política cultural es obra de todos, aunque hoy el agente productor y consumidor de la cultura se ha transformado. Tal vez por ello la cultura es un terreno resbaladizo de negociación de los cambios acelerados de la sociedad capitalista. El campo cultural se reconfigura como un conjunto de políticas, prácticas y discursos que opera, como otras estrategias gubernamentales, para gerenciar a la población, disciplinarla y reculturizarla en el consumo hedonista. El nuevo alcance y la prominencia de la cultura, la política y la agencia humana caseguran o posibilitan la democratización de la cultura?, ¿sus tramas coligan a las regiones para sobrevivir, competir o complementarse en la globalización? ${ }^{6}$

Para resumir digamos que si se "hinchan" voluntades para responder afirmativamente tales preguntas, se debe de subrayar que hacer cultura supone tres formas de acción irreductibles:

1) una forma de hacer política. En este sentido se habla de políticas culturales;

2) una forma de hacer economía que no necesariamente lleva a las políticas culturales a mimetizarse con la estética del mercado y la lógica publicitaria (Wortman, 2001:259); y, por último,

3) una forma de vida cuya estilización pasa por políticas de la cultura del desarrollo.

Como es evidente, estas últimas son las que subscribimos aquí, por suponer una política cultural radical — en el sentido de develar las raíces — o políticas públicas firmes para impulsar el desarrollo con equidad y seguridad a partir de potenciar las opciones y las utopías de los sujetos reales, su "estética terrena" (Willis, 1999).

Adagio sostenido. La cultura establece u obstaculiza pautas creativas y experiencias innovadoras que son correlativas al desarrollo histórico del hombre; al tiempo que el desarrollo del hombre es correlativo del desarrollo cultural de la sociedad como pautas estables y orden global. El desarrollo social es un haz de realidades emergentes y de lentos y continuos movimientos de opinión — reflexividad social—, de la gradual conciencia que alcanza todo actor social de sus problemas y las formas de resolverlos asumiendo costos y consecuencias. En este contexto, su historicidad es un hecho inminentemente cultural que (se) vivifica (con) la hechura de la historia y la acción social eficaz de todos los actores que participan en ella. Si estamos de acuerdo con lo comentado, se reducen las dudas sobre el primer plano en que se coloca la significación de las políticas culturales y de la cultura para la producción de lo social.

\section{Notas}

${ }^{1}$ Por ejemplo, en el NAFTA/TLCAM, el MERCOSUR y el Grupo de los Tres se contempla el incremento del intercambio cultural multinacional y se favorecen actividades conjuntas, convenios editoriales, televisivos, universitarios y de investigación. No obstante, sólo el MERCOSUR y la Unión Europea parecen avanzar en una integración cultural más real y efectiva (García Canclini, 1997:46; Miller y Yúdice, 2004:237-242).

${ }^{2}$ Por ejemplo, muchos programas acentúan la invisibilidad de las mujeres a partir del carácter asistencialista del enfoque del bienestar del Estado y de algunas ONG. Ello conduce a la necesaria impugnación del sesgo androcéntrico de la teoría y la praxis de las instituciones de desarrollo (Kottap, 2000:111, 113).

${ }^{3}$ Para ello habría que valorar en su medida tres claves de la cultura común, "tradicional" o "popular" (Willis, 1999), a saber: su carácter autónomo, compartido y creativo. Todo grupo social tiene una autonomía simbólica, es decir, tiende a organizar sus 
experiencias en un universo coherente dotado de sentido: posee gestos e ilusiones que lo autodefinen. Del mismo modo, todo sistema de prácticas, de lenguaje y de símbolos tiene un sentido cultural para los que comparten similares condiciones y posiciones sociales, dicho sentido se discute, se negocia y objetiva en estilos de vida, y en las definiciones que usamos en el lenguaje cotidiano para clasificar los tipos sociales. Por último, la cultura común tiene un carácter contradictorio como expresión del entrecruzamiento de relaciones de fuerza distintas, pero es una cultura de contestación, donde la creatividad intrínseca del ser humano puede traducirse en resistencia cultural con lo que ésta puede suponer de reproducción o no de unas relaciones de dominación dadas.

${ }^{4}$ Así, por ejemplo, los estudios culturales podrían contribuir a que las organizaciones y microempresas locales se colocasen directamente en los mercados nacionales e internacionales al promover de manera atractiva las expresiones culturales locales. La música, las artes, el diseño, la moda, la comida, la danza y los festivales son un campo de trabajo formidable apoyándose incluso en las posibilidades comerciales que ofrece Internet. La cultura y la innovación constituyen motores del crecimiento económico porque, entre otras cosas, requieren una alta demanda de mano de obra. Los trabajadores culturales buscan entornos creativos que por su lógica de intercambios fluidos de experiencias, propician la innovación, y complementos entre el sector de los servicios, la red de administradores y gestores que median ante las instituciones, otras entidades sociales y el público. ${ }^{5}$ Los estudios culturales latinoamericanos han subrayado que una de sus líneas de acción prioritarias es incrementar la información cultural disponible para poder armonizar políticas culturales en el nuevo contexto que ofrecen las telecomunicaciones, la interdependencia económica y las nuevas tecnologías. En este sentido resulta imprescindible hacer comparables los conceptos y categorías de los datos estadísticos culturales a nivel nacional y entre los países. La recolección de datos válidos, ayudaría a delimitar las cuentas de actividades culturales. Integrar a los censos nacionales la recolección de datos seleccionados sobre el patrimonio y sobre actividades culturales, estas últimas registradas también como sector económico y otorgando atención a los ejes de desigualdad. Promover la recolección de datos empíricos en los servicios sectoriales en todos los campos que se vinculan con la cultura, por ejemplo, importación y exportación de bienes culturales, educación artística, teatro y cine, y así sucesivamente en otros rubros.
${ }^{6}$ En este punto recuerdo la advertencia y la moraleja de la anécdota contada por Clifford Geertz: "Necesitamos una aprehensión más exacta de nuestro objeto de estudio si no queremos vernos en la situación de aquel personaje del cuento folklórico javanés, ese 'estúpido muchacho' que habiendo sido aconsejado por su madre de que buscara una esposa callada, regresó a su casa con un cadáver" (1987:173).

\section{Bibliografía}

Adelantado, José (coord.), 2000, Cambios en el Estado de Bienestar, Icaria\&Antrazyt-Universitat Autónoma de Barcelona, Barcelona.

Alburquerque Llorens, Francisco, 2004, "Desarrollo económico local y descentralización en América Latina.”, en Revista de la CEPAL, núm. 82, Abril, pp.157-171.

Alexander, Jeffrey C., 2000, Sociología cultural. Formas de clasificación en las sociedades complejas, Editorial AnthroposFLACSO, Barcelona.

Arocena, José, 1995, El desarrollo local: un desafío contemporáneo, Editorial Nueva Sociedad-CLAEH-universidad Católica del Uruguay, Venezuela.

Banco Mundial, 2004, Culture and Public Action/The Internacional Bank for Recosntruction and Development, Stanford University Press.

Barfield, Tomas (ed.), 2001, Diccionario de Antropología, Editorial Bellaterra, Barcelona.

Bourdieu, Pierre, 2004, "Carta abierta al director general de la UNESCO sobre las amenazas que hace pesar la AGCS", en Intervenciones, 1961-2001. Ciencias Social y Acción Política, Editorial Hiru-Ciencias Sociales, Hondarribia, pp.554-558.

—, 1995, "Double bind y conversión”, en Pierre Bourdieu y Loïc J.D. Wacquant, Respuestas por una antropología reflexiva, Editorial Grijalbo, México, pp.185-190.

—, 1993, "El campo intelectual: un mundo aparte", en Cosas dichas, Editorial Gedisa, Barcelona, pp.143-151.

Bueno, Gustavo, 1997, El mito de la cultura, Editorial Prensa Ibérica, Barcelona.

Caetano, Gerardo, 2003, "Políticas culturales y desarrollo social. Algunas notas para revisar conceptos", en Pensar Iberoamérica. Revista de cultura, núm. 4, Junio-Septiembre, Organización de Estados Iberoamericanos para la Educación, la Ciencia y la Cultura (OEI), Madrid. 
Calderón, Fernando y Alicia Szmukler, 2004, “Ciudadanía activa y desarrollo sostenible”, en Waldo Ansaldi coord.), Calidoscopio Latinoamericano. Imágenes históricas para un debate vigente, Editorial Ariel, Buenos Aires, pp.219-449.

Cambra Bassols, Jordi de y Ernel González Mastrapa, 2000, Desarrollo Humano, Cultura y Participación, Conferencia Internacional "Desarrollo Humano Sostenible", Cátedra unEsCo, Universidad de La Habana, junio.

Cambra Bassols, Jordi de, 2002, Desarrollo y subdesarrollo del concepto de desarrollo: elementos para una reconceptualización. [mec.]. Carranza, Julio, 1999, "Cultura y desarrollo", en Revista Temas, núm. 18-19, La Habana, 1999, pp.29-38.

Castel, Robert, 1997, Las metamorfosis de la cuestión social. Una crónica del salariado, Editorial Piadós, México.

Castells, Manuel, 1995, La ciudad internacional: tecnologías de la información, reestructuración económica y el proceso urbano-regional, Editorial Alianza, Madrid.

Celecia, John y Dominique Richard, 1997, Redefining Concepts, Challenges and Practices of Urban Sustainability, European Foundation for the Improvement of Living and Working Conditions, Luxembourg.

Fuentes, Carlos, 1997, Introducción a documento del Programa de Cultura de la UNESCO, uNESCO, París.

García Canclini, Néstor, 1987, Las Politicas Culturales en América Latina y el Caribe, Grijalbo, México.

—, 1997, "El malestar en los estudios culturales", en Revista Fractal, núm. 6, julio-septiembre, año 2, volumen II, México, pp. 45-60.

—, 1999, "Opciones de políticas culturales en el marco de la globalización”, en Informe Mundial sobre la Cultura. Cultura, creatividad y mercados, Editorial unEsCO, París.

—, 2000, La globalización imaginada, Editorial Piadós, Buenos Aires.

—, 2001, "Definiciones en Transición”, en Daniel Mato (comp.),

Estudios latinoamericanos sobre cultura y transformaciones sociales en tiempos de globalización, CLACSO-ASDI, Buenos Aires, pp.69-89.

Geertz, Clifford, 1987, La interpretación de las culturas, Editorial Gedisa, Barcelona.

Getino, Octavio, 2003, "Las industrias culturales, entre el proteccionismo y la autosuficiencia", en Pensar Iberoamérica. Revista de cultura, núm. 4, Junio-Septiembre, Organización de Estados Iberoamericanos para la Educación, la Ciencia y la Cultura (OEI), Madrid.
Gouldner, Alvin, 1980, El futuro de los intelectuales y el ascenso de la nueva clase, Editorial Alianza, Madrid.

Gray, John, 2004, “Una Ilusión con Futuro”, en Letras Libres, núm. 71, Año VI, México, pp.12-17.

Grignon, C. y J.C. Passeron, 1991, Lo culto y lo popular, Editorial Nueva Visión, Buenos Aires.

Hopenhayn, Martín, 2001, “¿Integrarse o subordinarse? Nuevos cruces entre política y cultura”, en Daniel Mato (comp.), Estudios latinoamericanos sobre cultura y transformaciones sociales en tiempos de globalización, CLACSO-ASDI, Buenos Aires, pp.69-89.

Inglehart, Ronald, 1991, El cambio cultural en las sociedades industriales avanzadas, CIS- Siglo XXI, Madrid.

Kottak, Conrad P., 2000, "La cultura y el 'desarrollo económico”, en Andreu Viola, Antropología del desarrollo. Teoría y estudios etnográficos en América Latina, Editorial Piadós, Barcelona, pp.103-126.

Mattelart, Armand y J.P. Piemme, 1985, "Veintitrés notas para un debate político sobre la comunicación”, en M.Moragas (ed.), Sociología de la comunicación de masas, Vol. IV, Editorial Gustavo GIli, Barcelona.

Miller, Toby y George Yúdice, 2004, Politica Cultural, Editorial Gedisa, Barcelona.

Piedras, Ernesto, 2004, ¿Cuánto vale la cultura? Contribución económica de las industrias culturales protegidas por el derecho de autor en México, CONECULTA-SACM-SOGEM-CNIEM, México.

PNUD, 1990-1998, Informes sobre Desarrollo Humano, MundiPrensa, Madrid.

Sen, Amaryta, 2004, “¿Cómo importa la cultura en el desarrollo?”, en Letras Libres, núm. 71, Año VI, México, pp. $23-30$.

unesco, 1996, Nuestra Diversidad Creativa, Informe de la Comisión Mundial de Cultura y Desarrollo, unesco, París.

UNESCO, 1998, Intergovernmental Conference on Cultural Policies for Development, Estocolmo 30-03 a 02-04-98, CLT-98/ Conf.210/3.

Vázquez Barquero, Antonio, 2002, Endogenous Development, Routledge, London and New York.

Viola, Andreu, 2000, "La crisis del desarrollo y el surgimiento de la antropología del desarrollo.” En: Andreu Viola (comp.), Antropología del desarrollo. Teoría y estudios etnográficos en América Latina, Editorial Piadós, Barcelona, pp. 1-30. 
West, Cornel, 2002, "Las nuevas políticas culturales de la diferencia”,.en Revista Temas, núm. 28, enero-marzo, La Habana, pp. 4-14.

Willis, Paul, 1999, "Notas sobre cultura común. Hacia una nueva política cultural para la estética terrena", en Revista Arxius de Sociología, Departamento de Sociología y Antropología Social, Universitat de Valencia, núm. Juny, pp.15-32.

World Commission on Environment and Development, 1987, Our Common Future, Oxford University Press, Oxford. Wortman, Ana, 2001, "El desafío de las políticas culturales en la Argentina”, en Daniel Mato (coord.), Cultura y transformaciones sociales en tiempos de globalización 2, CLACSO-ASDI, Venezuela, pp.251-267.

Yúdice, George, 2002, El recurso de la cultura. Usos de la cultura en la era global, Editorial Gedisa, Barcelona.

Zallo, Ramón, 2003, "Nuevas políticas para la diversidad: las culturas territoriales en riesgo por la globalización", en Pensar Iberoamérica. Revista de cultura, núm. 4, Junio-Septiembre, Organización de Estados Iberoamericanos para la Educación, la Ciencia y la Cultura (OEI), Madrid. 